\title{
25 Research Soure \\ Finite Element Modeling and Vibration Analysis of Sprag Clutch-Flexible Rotor System
}

chuang huang

Harbin Institute of Technology;Gree Electric Appliances,Inc. of Zhuhai

yongqiang zhao ( $\square$ zhyqhit@hit.edu.cn )

Harbin Institute of Technology https://orcid.org/0000-0002-8317-5409

guanghu jin

National Key Laboratory of Science and Technology on Helicopter Transmission, Nanjing University of Aeronautics and Astronautics

\section{Original Article}

Keywords: Sprag clutch-rotor system, Finite element model, Unbalanced mass, Experimental verification

Posted Date: October 28th, 2020

DOl: https://doi.org/10.21203/rs.3.rs-96922/v1

License: (c) (1) This work is licensed under a Creative Commons Attribution 4.0 International License.

Read Full License 


\section{Abstract}

To study the overall vibration characteristics of the sprag clutch-flexible rotor system (SC-FRS) under high-speed operating conditions, a finite element model of SC-FRS considering rotor flexibility and bearing support stiffness is established based on the proposed calculation method of the stiffness matrix. According to this model, the natural frequency and mode shape of the system are calculated, and the correctness of the model is verified by comparing it with the calculation results of ANSYS software. Under the action of unbalance, the bending-torsion coupled vibration and the dynamic load of the intershaft bearings are analyzed, and it is found that the resonant peak in the torsional direction has the same resonance frequency as that in the bending direction. A test rig for the sprag clutch-rotor system is built, and the axis trajectory and critical speed are tested. The test results show that the finite element model of SC-FRS can accurately describe the vibration characteristics of the system.

\section{Full Text}

Due to technical limitations, full-text HTML conversion of this manuscript could not be completed. However, the manuscript can be downloaded and accessed as a PDF.

\section{Table}

Table 1

Natural frequency of rotor system calculated by various models

\begin{tabular}{|llll|}
\hline Order & The proposed model $(\mathrm{Hz})$ & The ANSYS model $(\mathrm{Hz})$ & Relative error \\
\hline 1 & 168.8 & 168.4 & $0.24 \%$ \\
\hline 2 & 169.5 & 169.9 & $0.24 \%$ \\
\hline 3 & 538.2 & 539.5 & $0.24 \%$ \\
\hline 4 & 538.5 & 540.1 & $0.30 \%$ \\
\hline 5 & 604.0 & 605.0 & $0.17 \%$ \\
\hline 6 & 604.2 & 605.3 & $0.18 \%$ \\
\hline
\end{tabular}

\section{Figures}




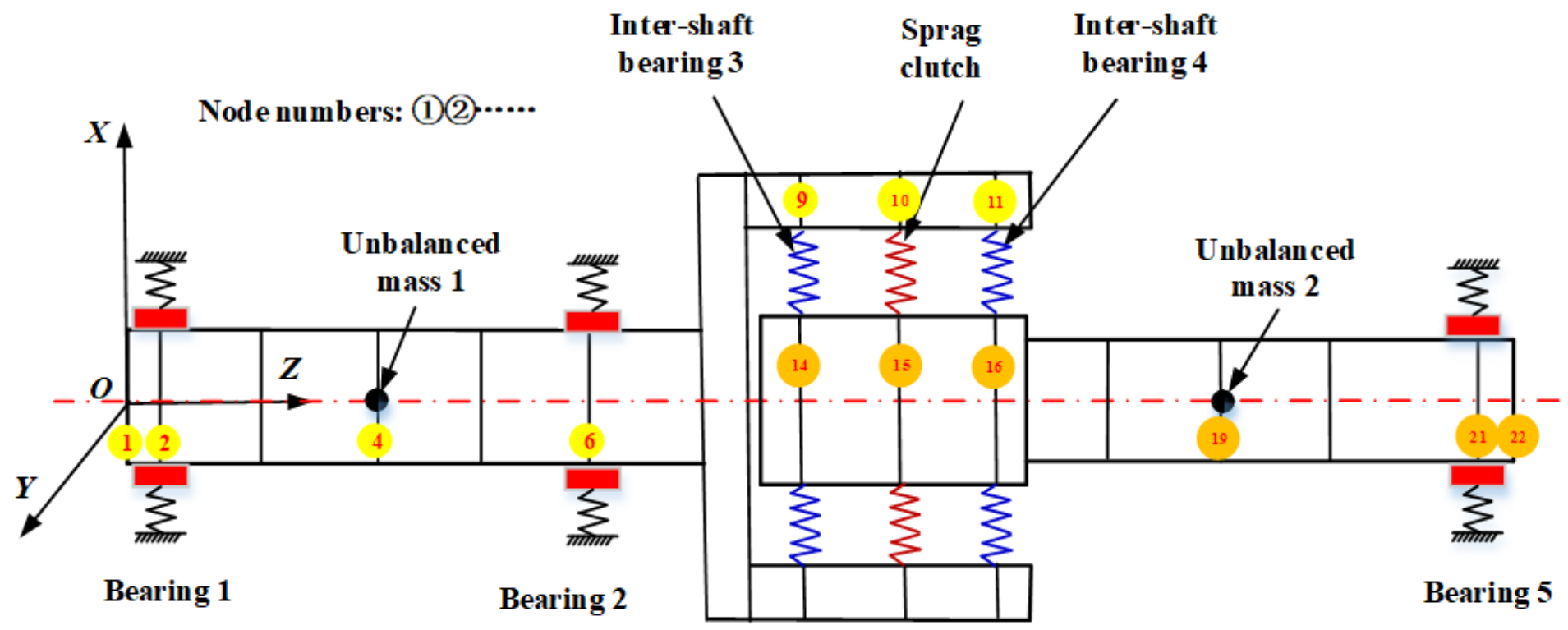

Figure 1

Schematic diagram of the division for the finite element unit of the system
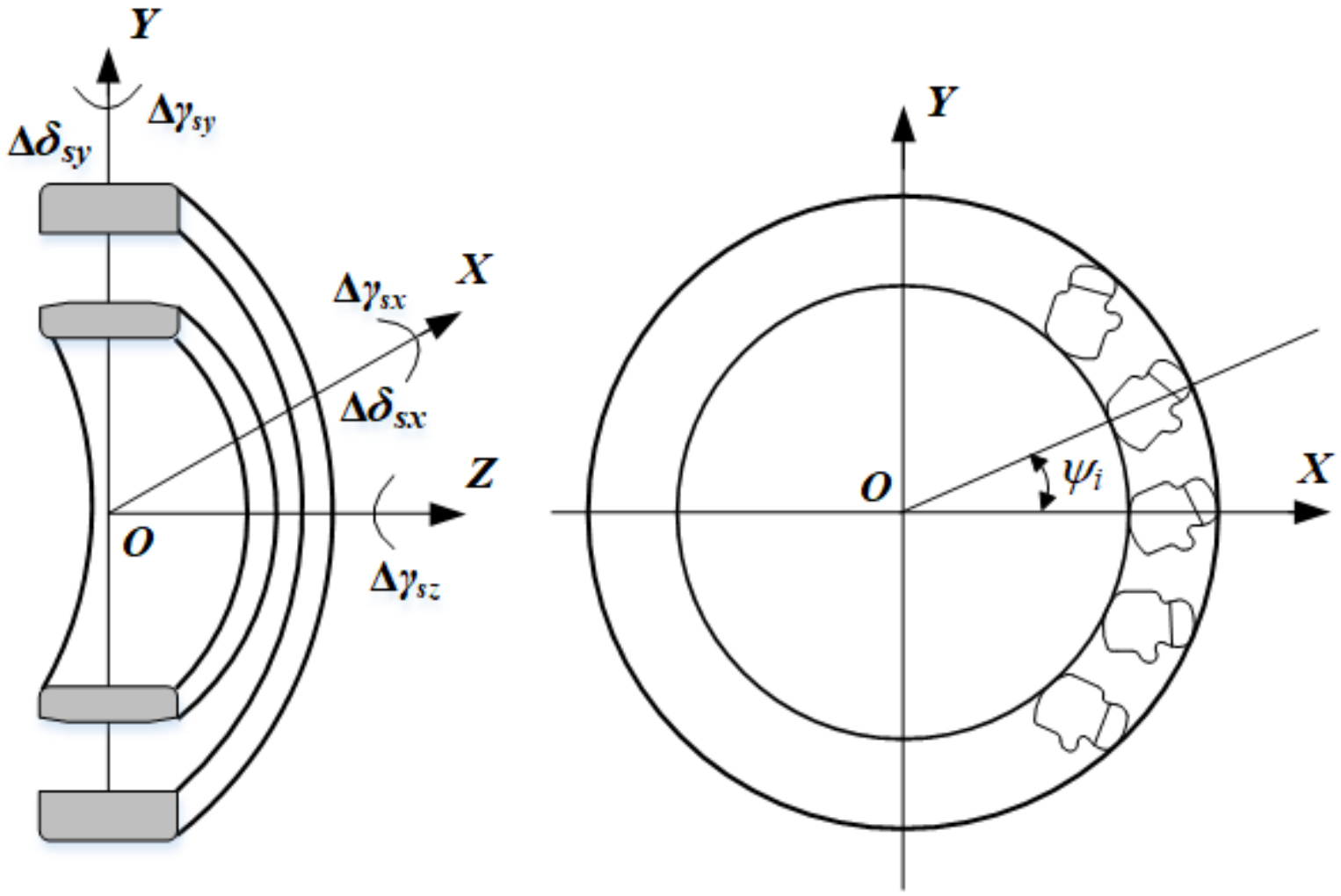

Figure 2

Coordinate system and degrees of freedom of the sprag clutch 


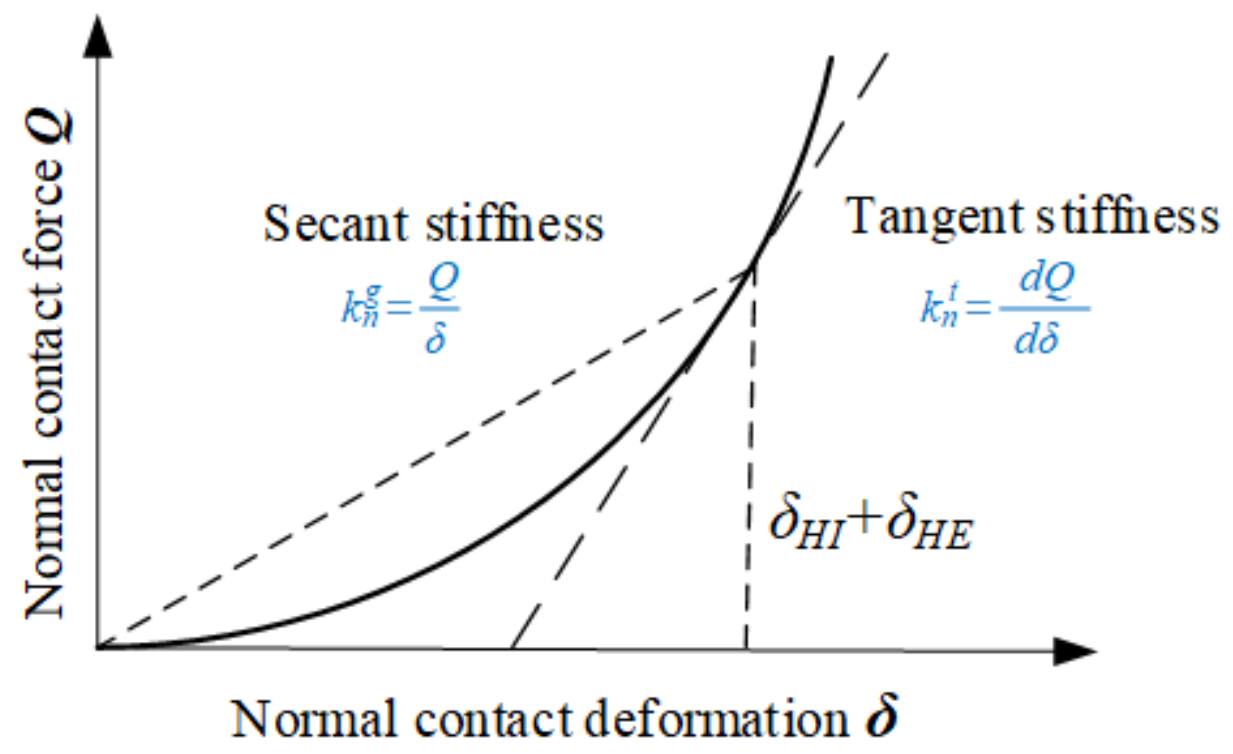

Figure 3

Tangential stiffness corresponding to pre-contact deformation

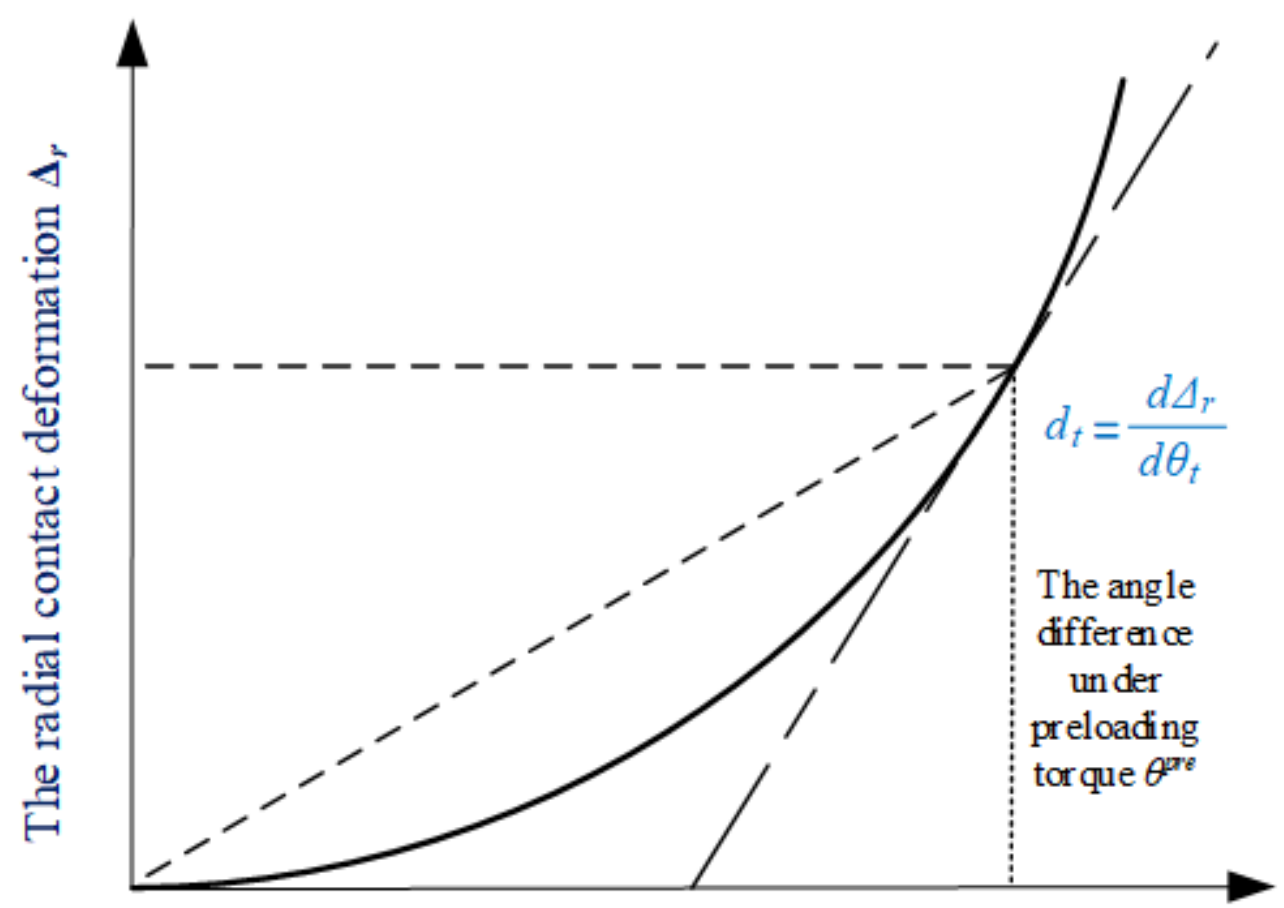

The angle difference of the inner and outer rotors $\theta_{t}$

Figure 4

Radial deformation coefficient under preloading torque 


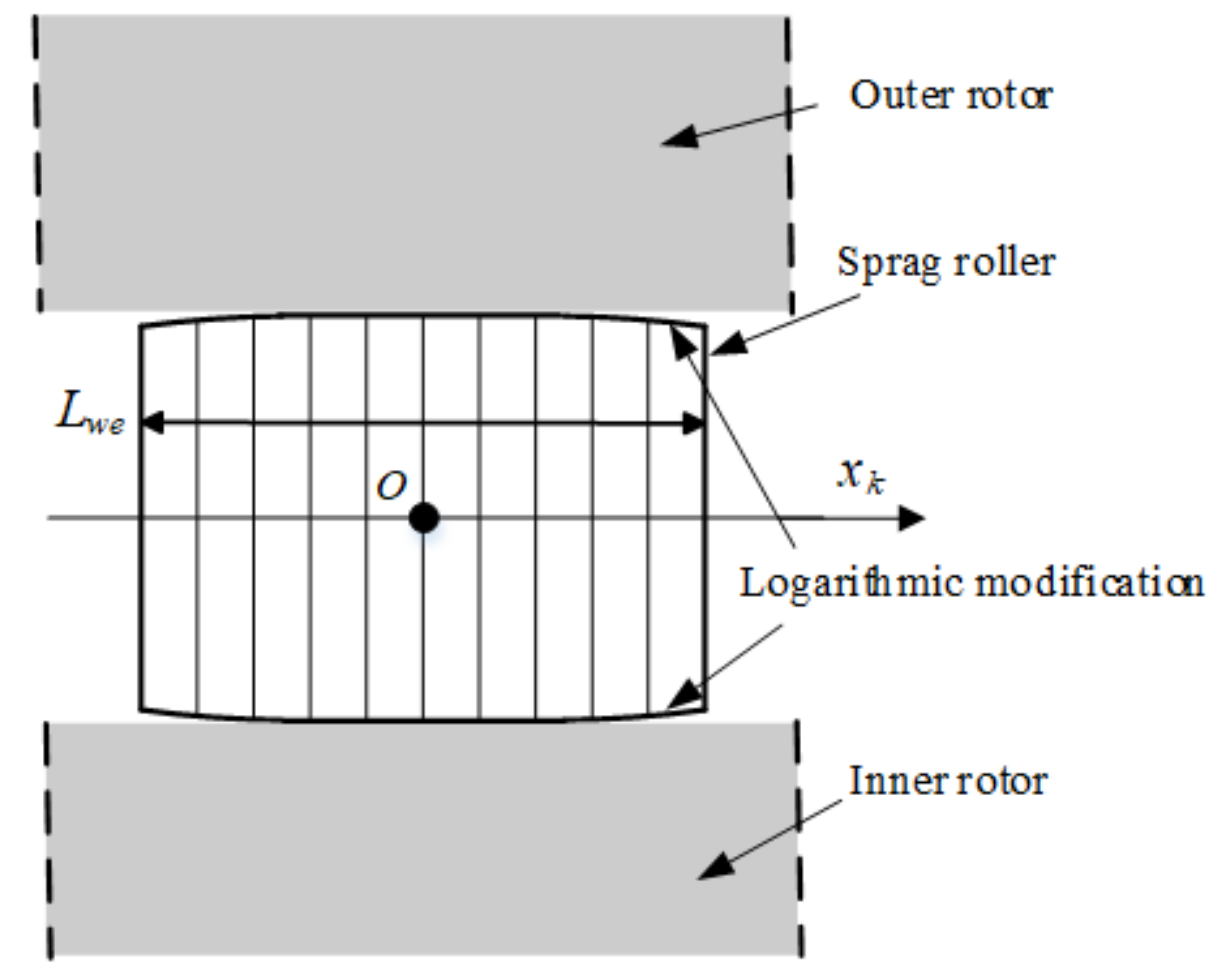

Figure 5

Division of the slices in the axial direction of the sprag roller 
Bearing with fixed outer ring

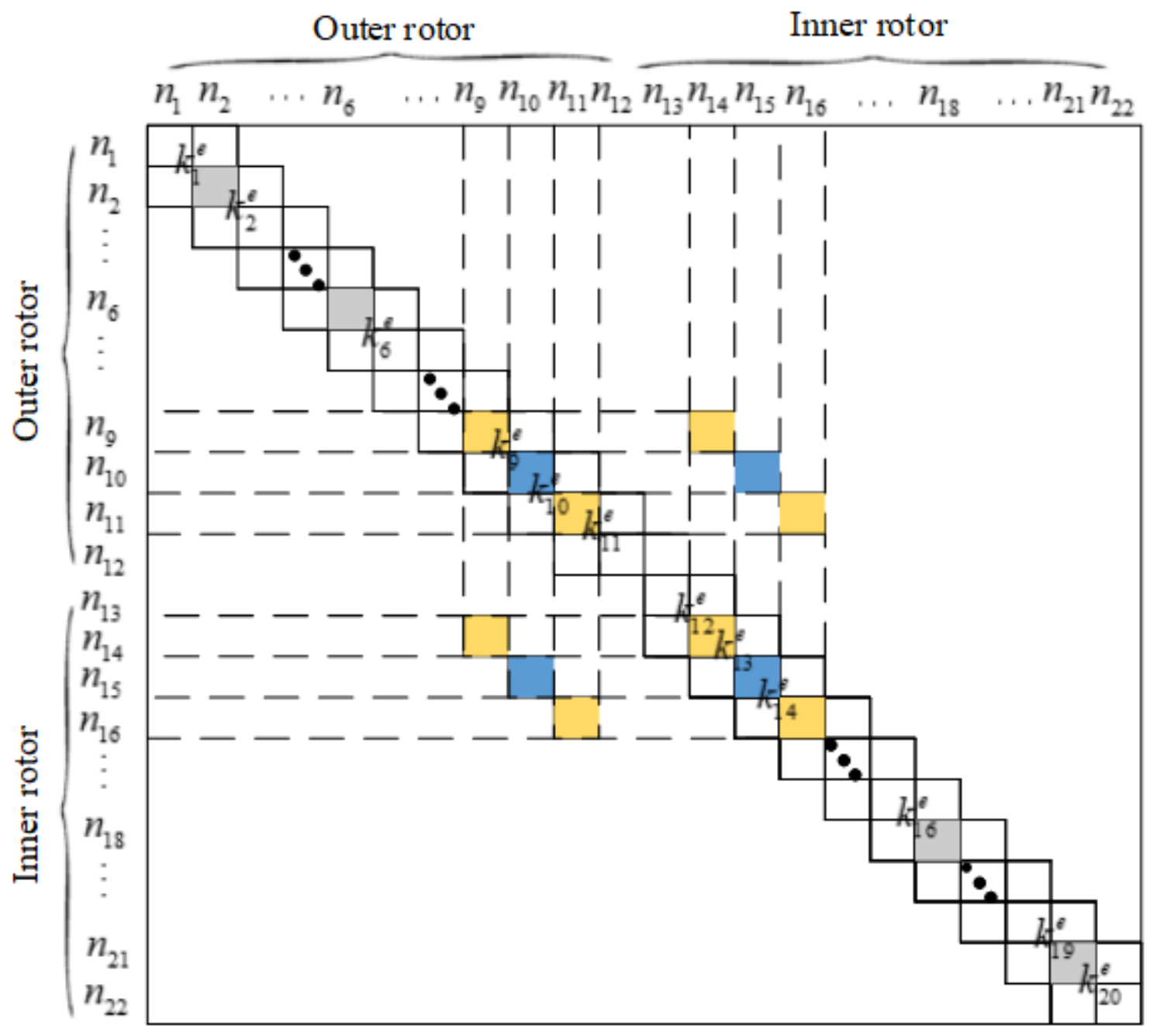

Figure 6

Schematic diagram of the assembly of the stiffness matrix 
a

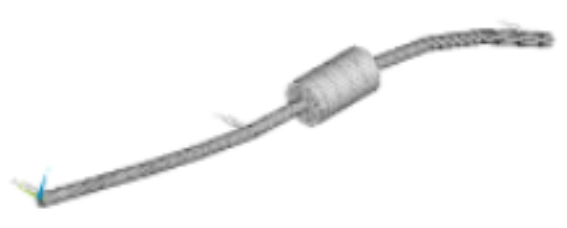

c
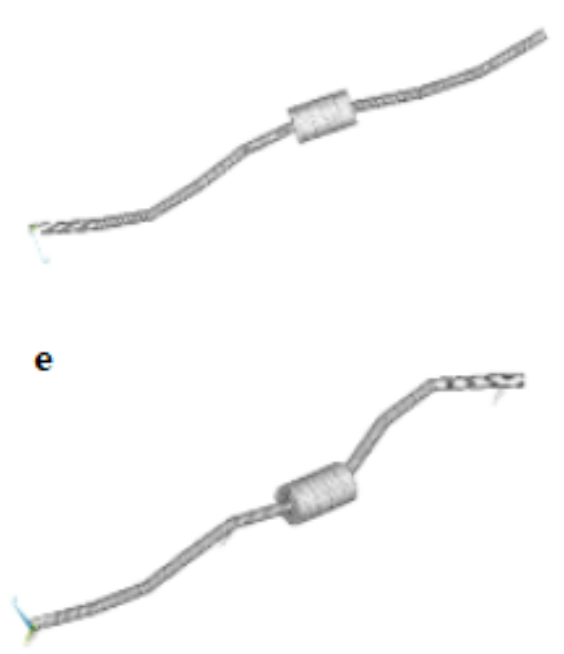

b

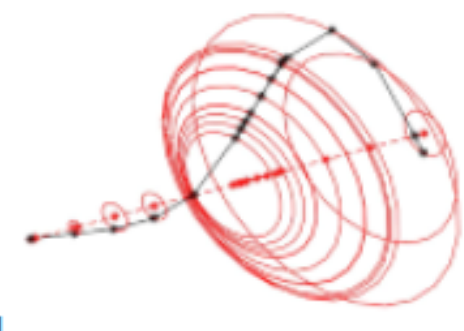

d

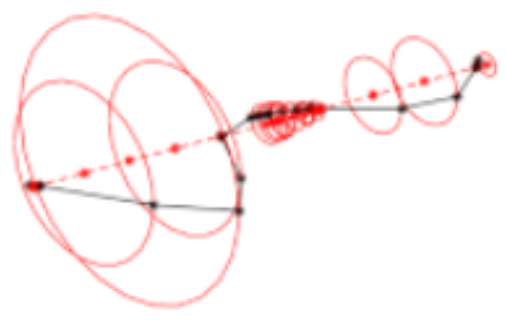

f

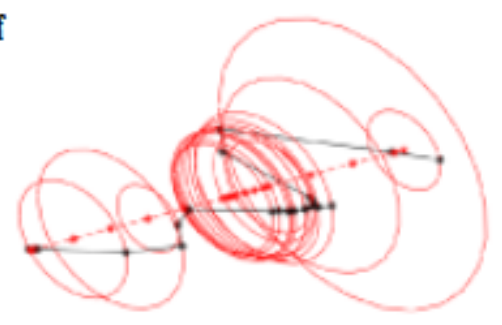

\section{Figure 7}

Representative mode shapes of the system: $a, c, e$ The first, third, fifth mode shapes of ANSYS model; $b$, $d, f$ The first, third, fifth mode shapes of the proposed model

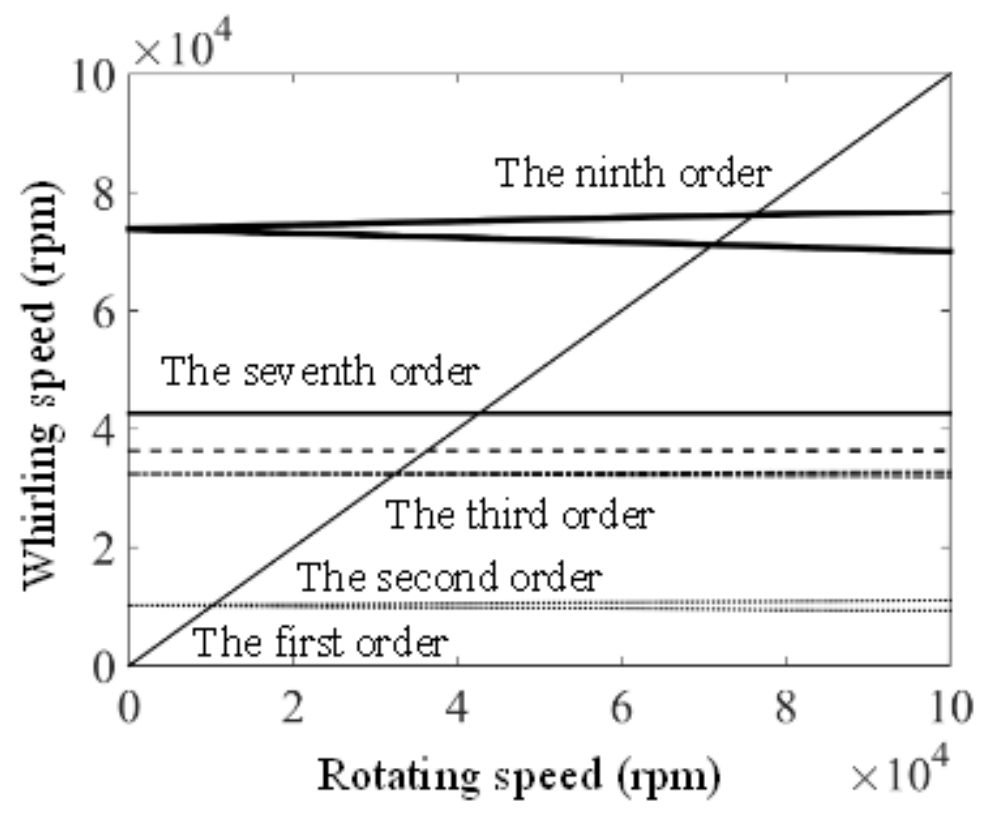


Figure 8

Campbell diagram of rotor system with sprag clutch

a

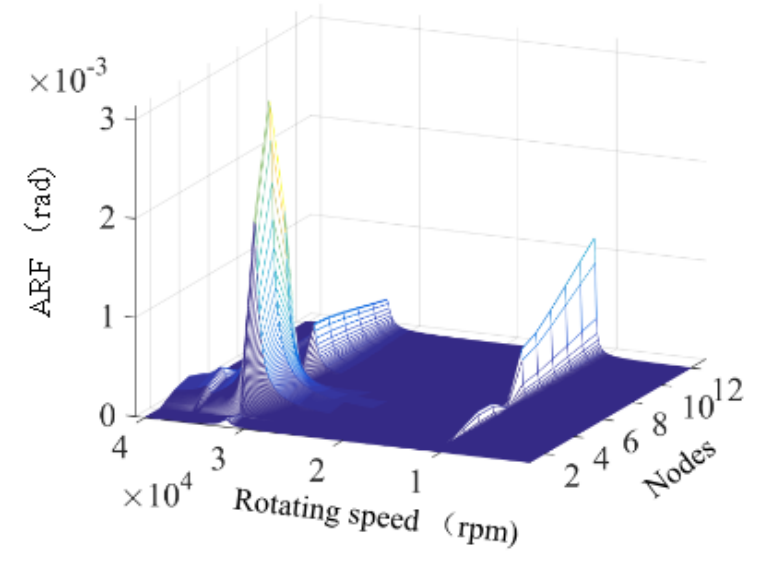

c

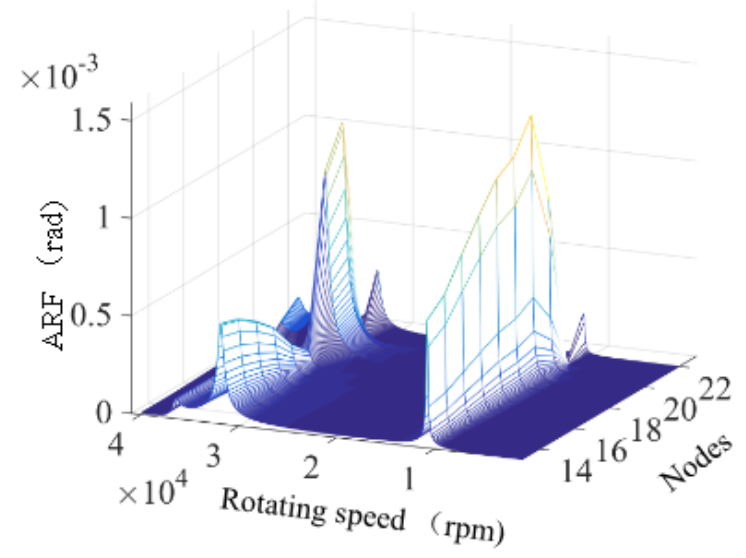

b

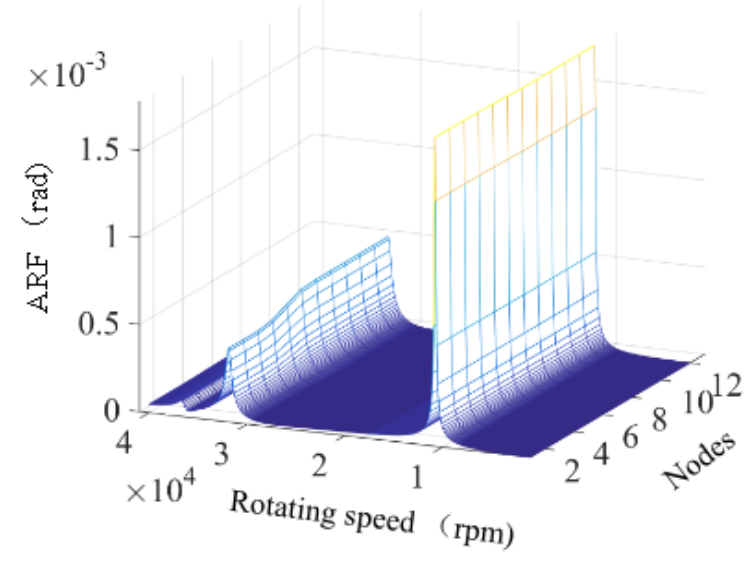

d

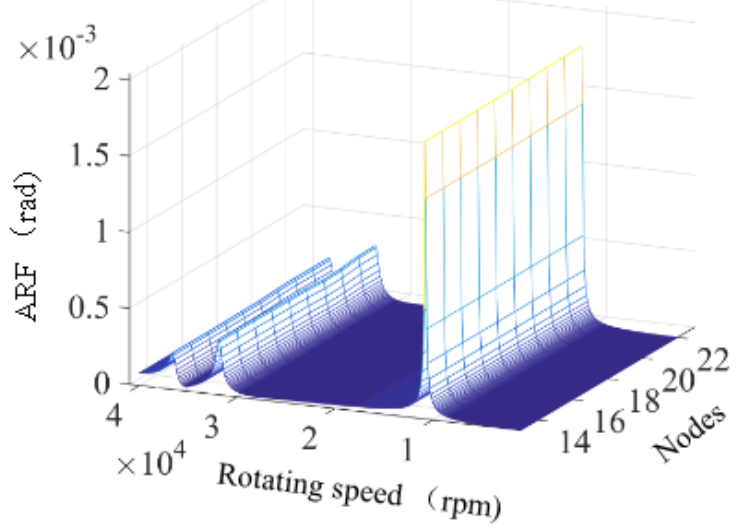

\section{Figure 9}

AFR of all nodes in the $x$ and $\theta z$ directions: $a, c$ In the $x$ direction of nodes on the outer and inner rotors; $b$, $d$ In the $\theta z$ direction of nodes on the outer and inner rotors 
a

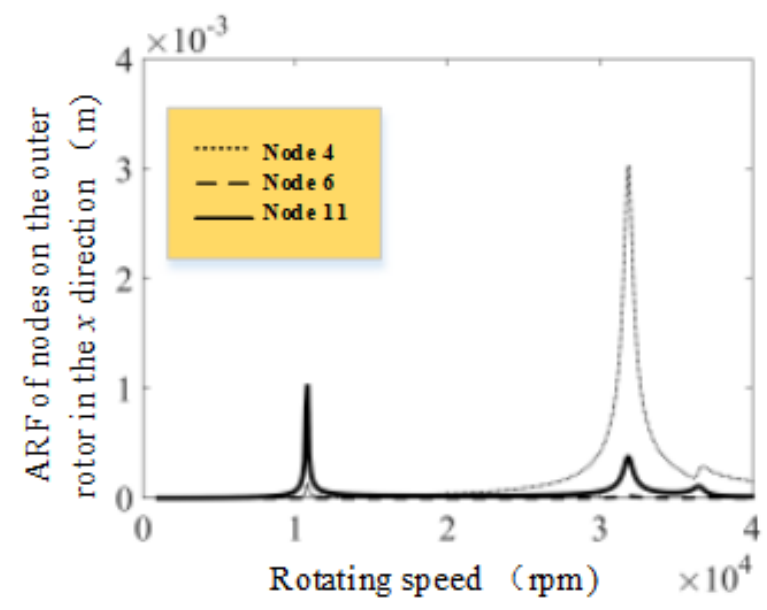

c

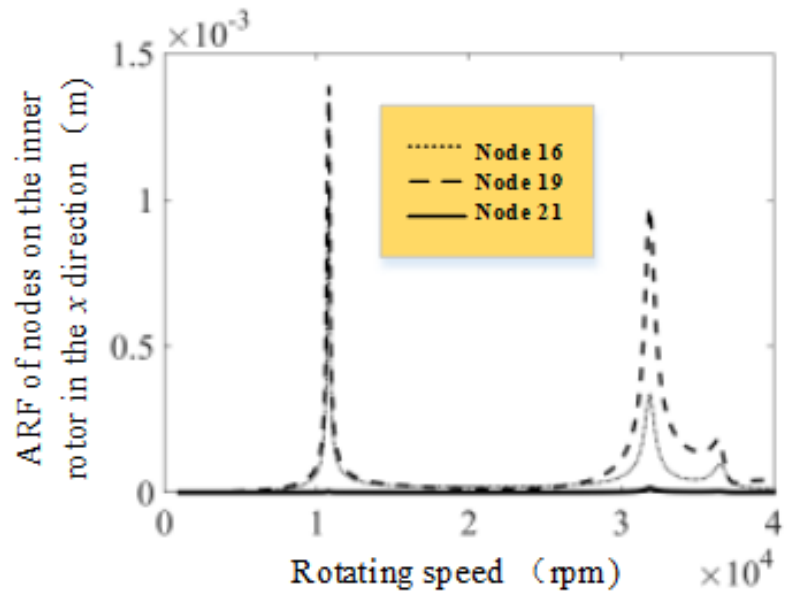

b

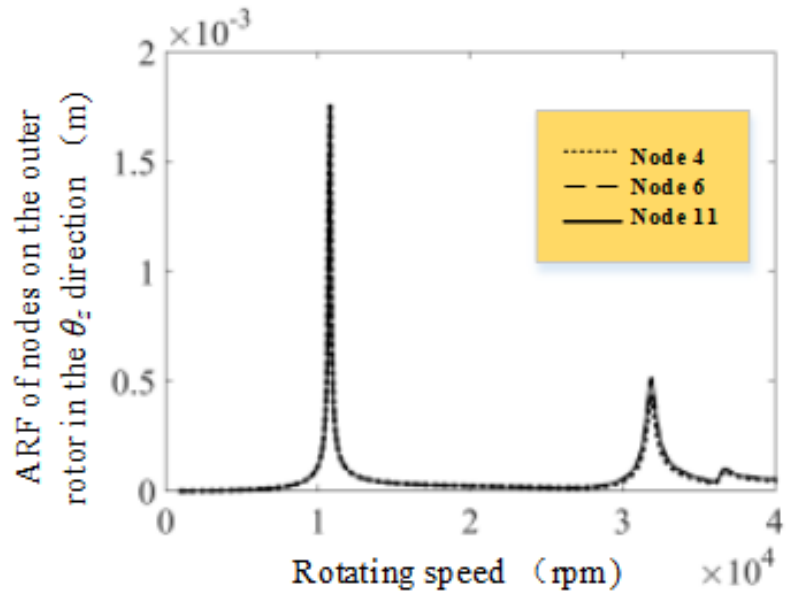

d

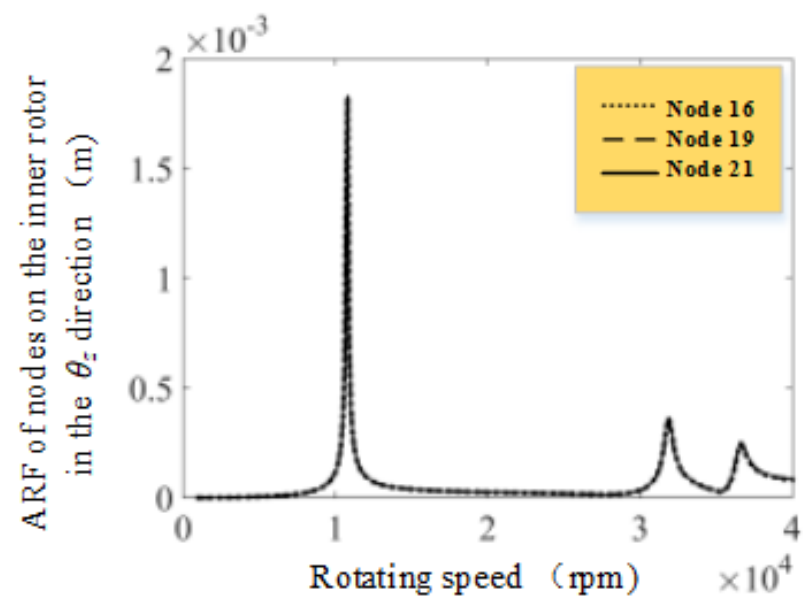

Figure 10

AFR of special nodes in the $x$ and $\theta z$ directions: $a, c$ In the $x$ direction of nodes on the outer and inner rotors; $b, d$ In the $\theta z$ direction of nodes on the outer and inner rotors 
a

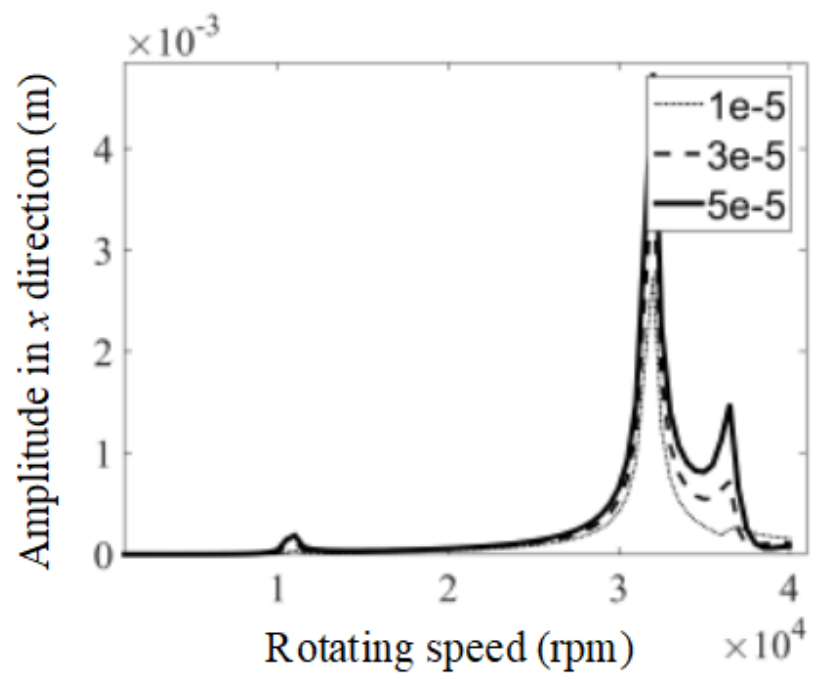

C

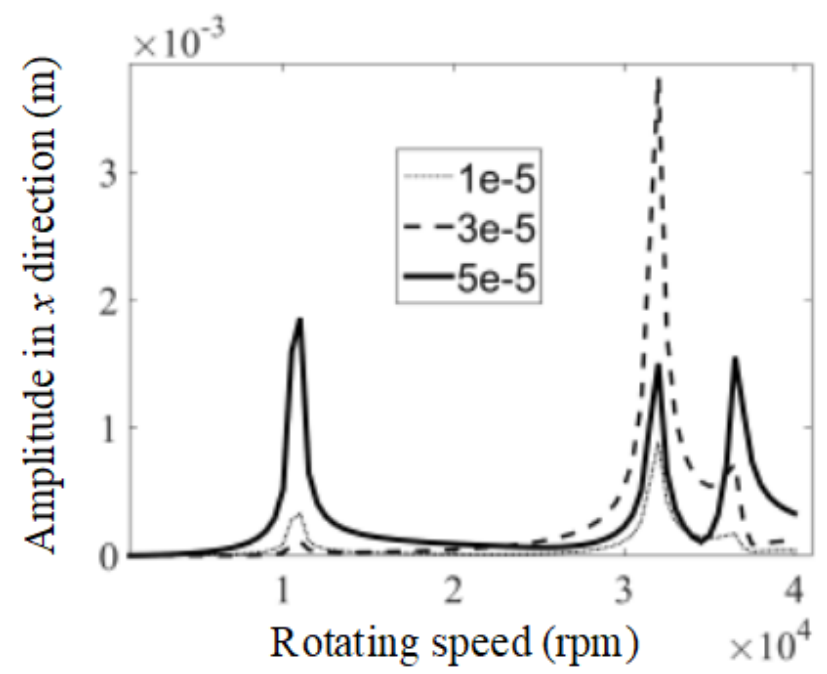

b

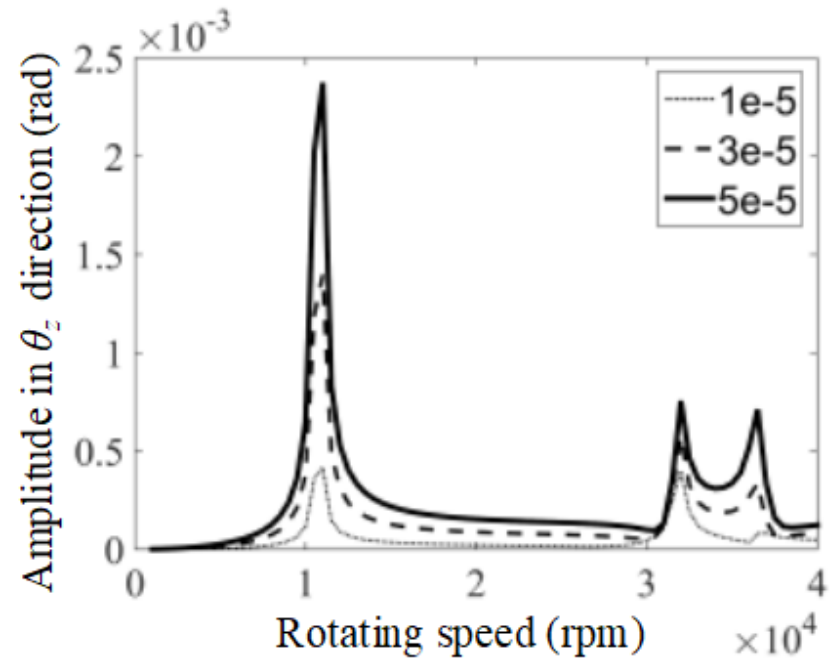

d

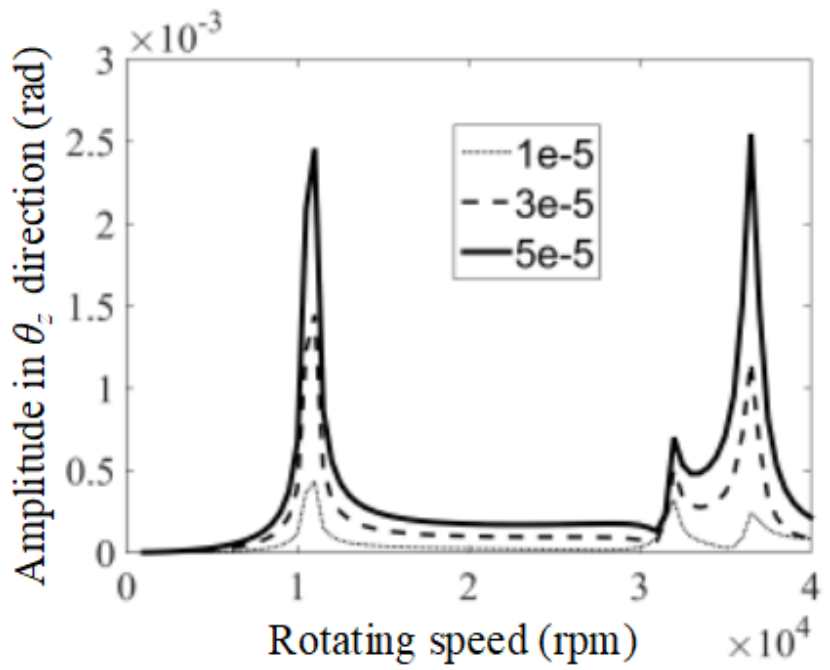

Figure 11

AFR of nodes 4 and 19 in the $x$ and $\theta z$ direction under unbalanced mass 2: a, c In the $x$ direction of node 4 and $19 ; b, d$ In the $\theta z$ direction of node 4 and 19 

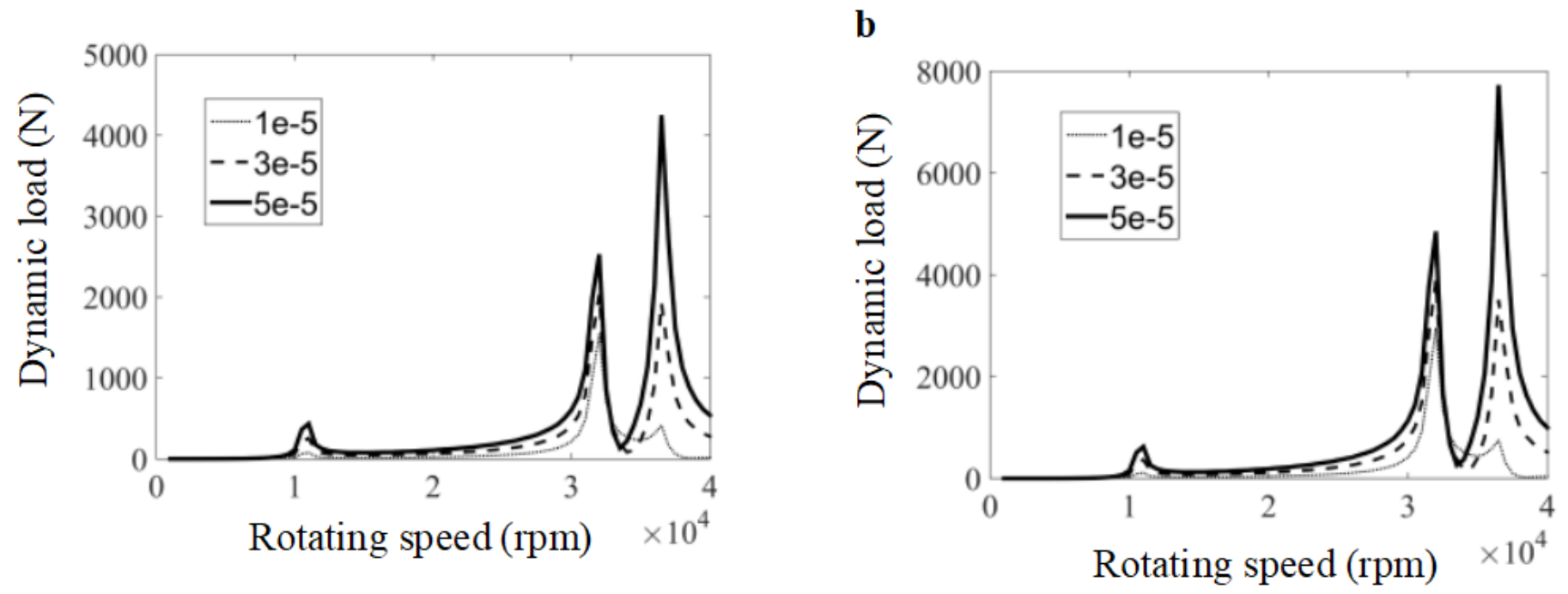

Figure 12

AFR of the dynamic load of the inter-shaft bearing in $x$ direction under unbalanced mass 2: a The intershaft bearing 3; $b$ The inter-shaft bearing 4

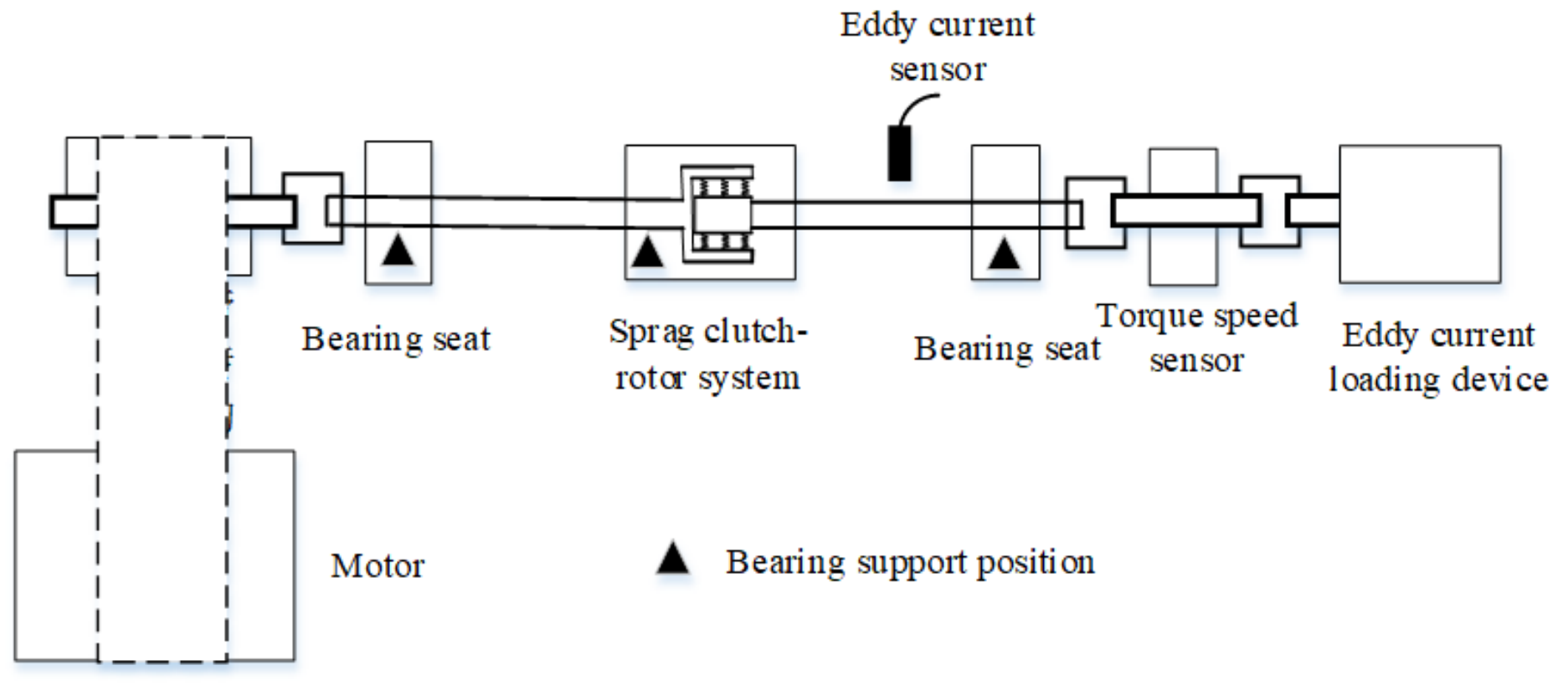

Figure 13

Schematic of the test bench of sprag clutch-rotor system 


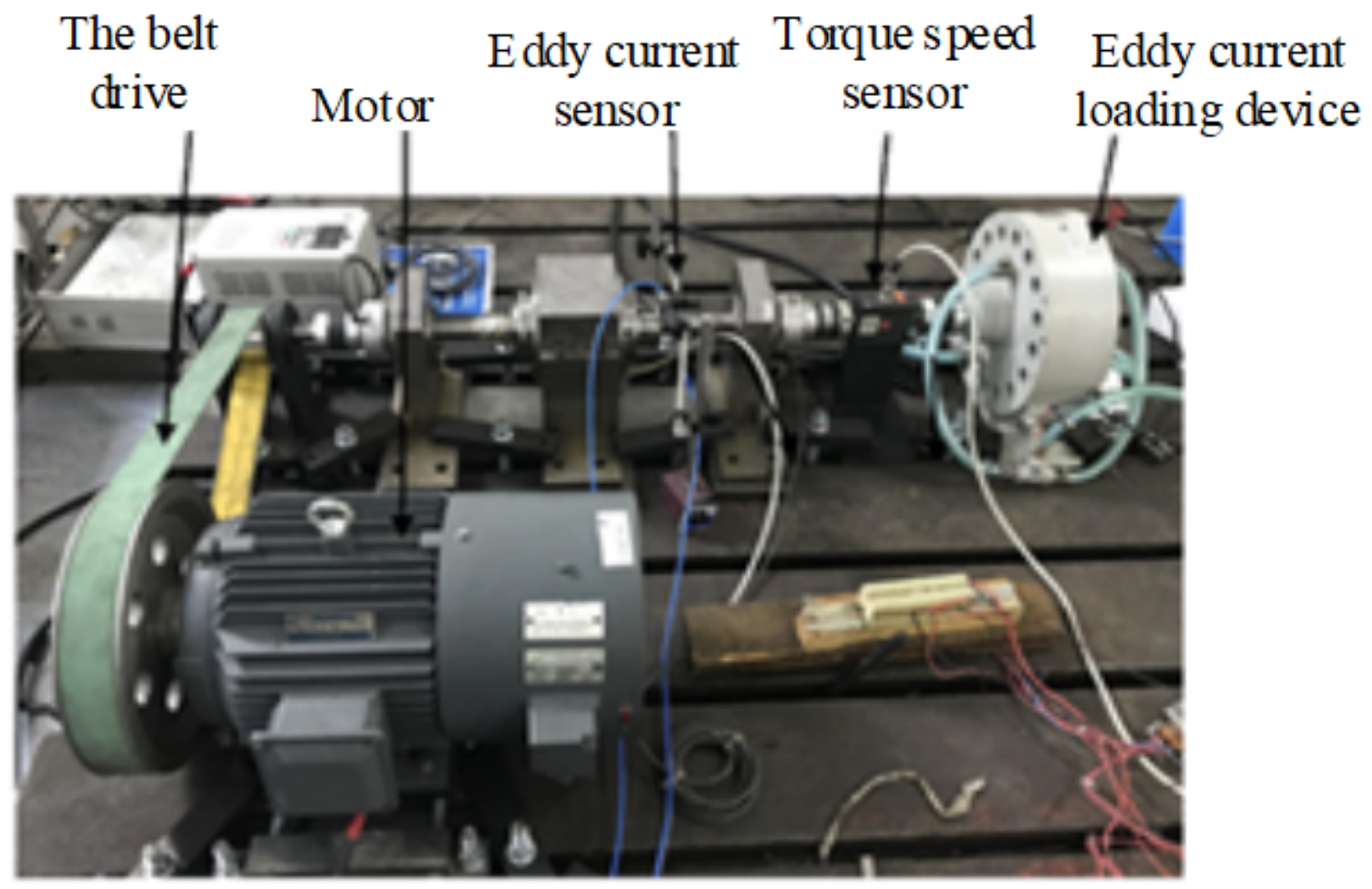

Figure 14

The test bench of sprag clutch-rotor system

a

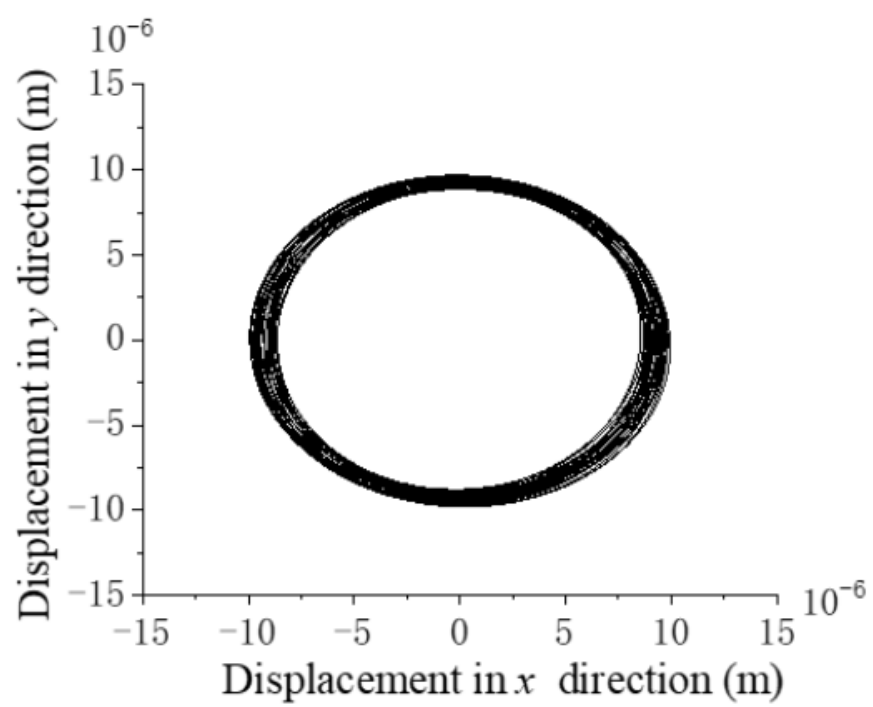

b

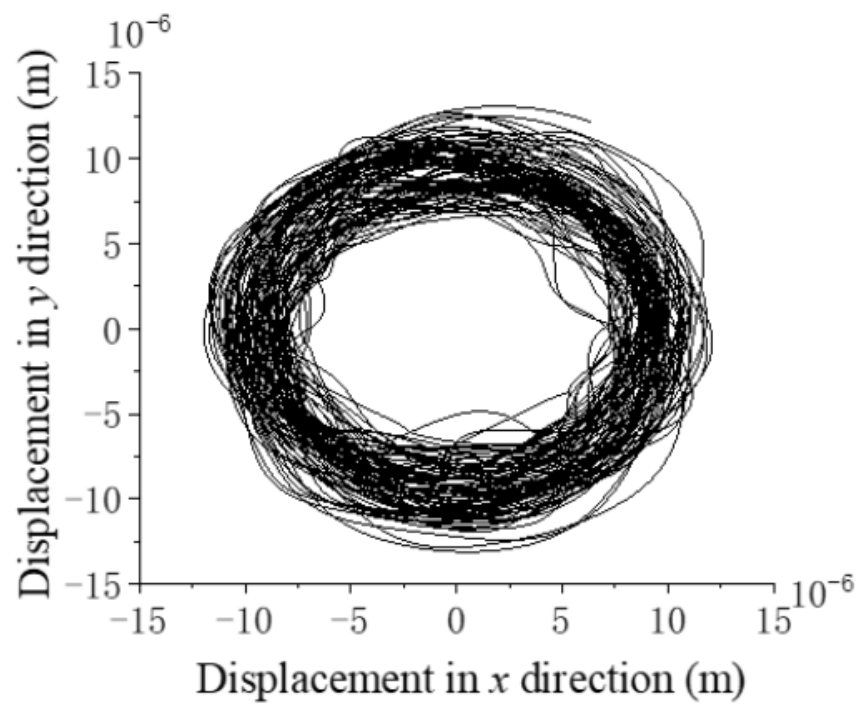

Figure 15

The test bench of sprag clutch-rotor system 


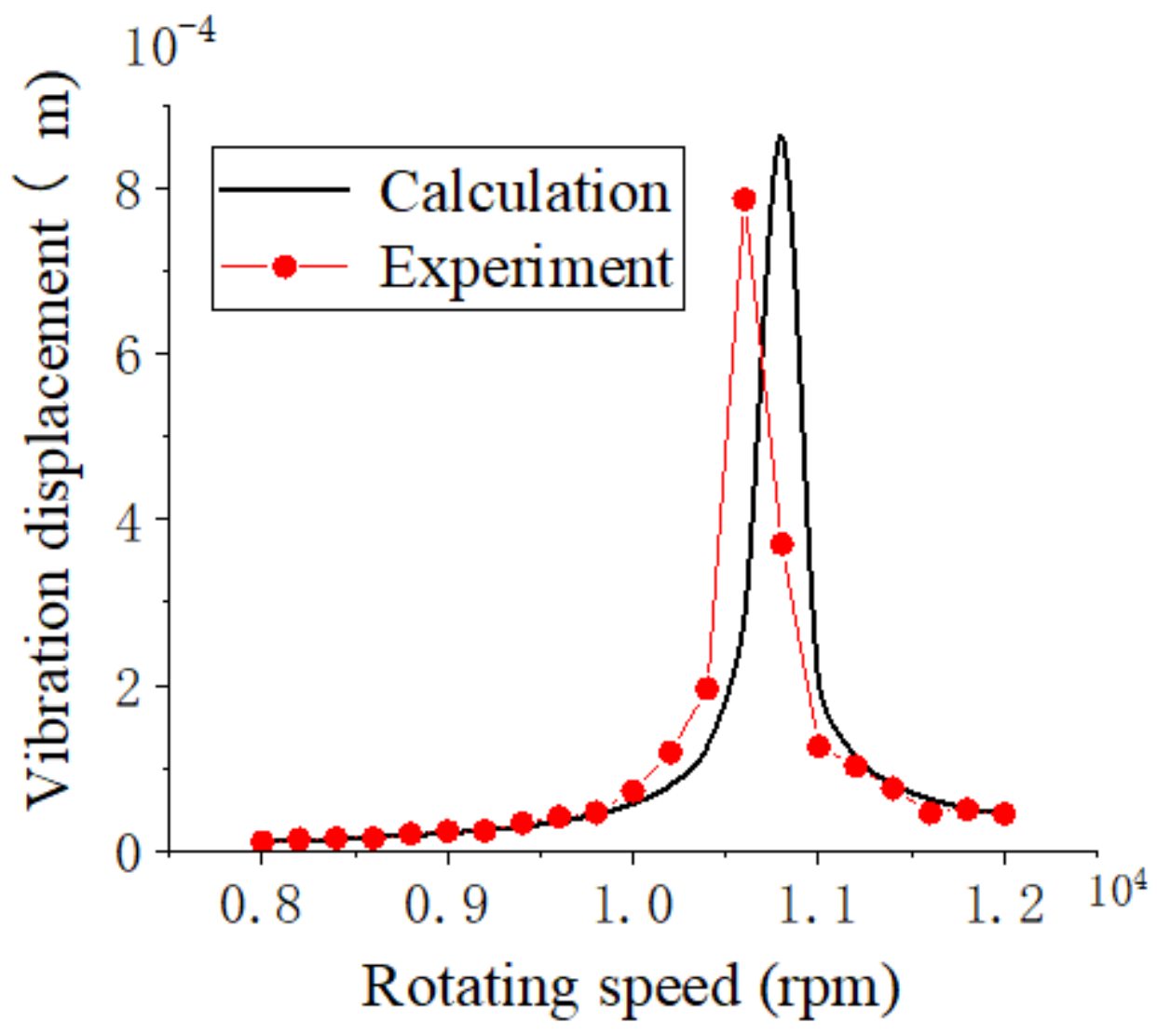

Figure 16

Comparison of critical speed of SC-FRS between theoretical calculation and experiment of the $\mathrm{x}$-direction 